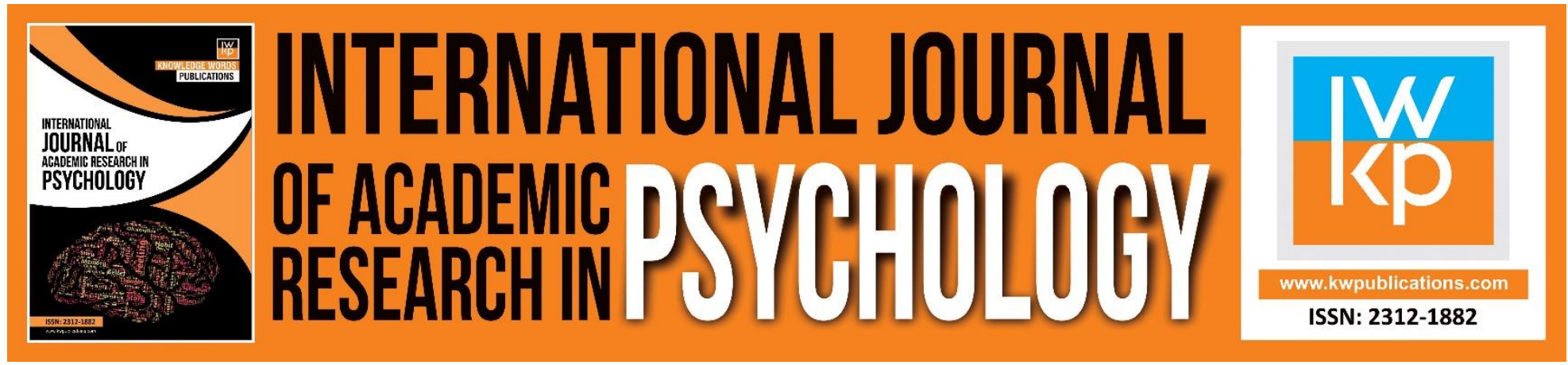

\title{
Working Memory Capacity-Induced Errors in Children's Analogical Reasoning: Implications for Learning Outcome
}

\author{
Stephen Ntim, Mavis Okyere
}

To Link this Article: http://dx.doi.org/10.46886/IJARP/v2-i1/1620

DOI:10.46886/IJARP/v2-i1/1620

Received: 11 January 2015, Revised: 14 February 2015, Accepted: 12 March 2015

Published Online: 30 March 2015

In-Text Citation: (Ntim \& Okyere, 2015)

To Cite this Article: Ntim, S., \& Okyere, M. (2015). Working Memory Capacity-Induced Errors in Children's Analogical Reasoning: Implications for Learning Outcome. International Journal of Academic Research in Psychology, 2(1), 1-19.

\section{Copyright: (c) 2015 The Author(s)}

Published by Knowledge Words Publications (www.kwpublications.com)

This article is published under the Creative Commons Attribution (CC BY 4.0) license. Anyone may reproduce, distribute, translate and create derivative works of this article (for both commercial and non-commercial purposes), subject to full attribution to the original publication and authors. The full terms of this license may be seen

at: http://creativecommons.org/licences/by/4.0/legalcode

Vol. 2, No. 1, 2015, Pg. 1- 19

https://kwpublications.com/journals/journaldetail/IJARP

JOURNAL HOMEPAGE

Full Terms \& Conditions of access and use can be found at https://kwpublications.com/pages/detail/publication-ethics 


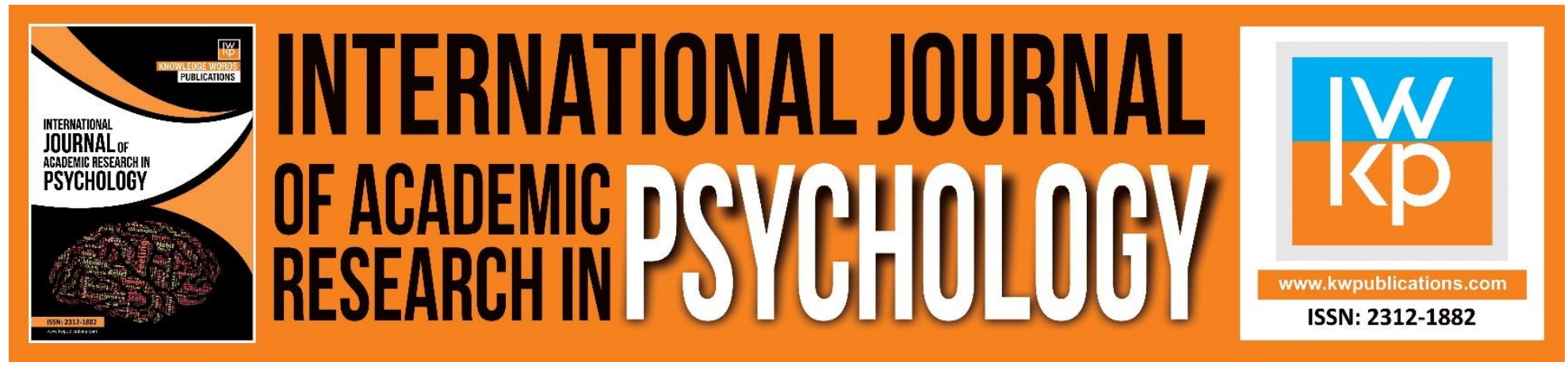

\title{
Working Memory Capacity-Induced Errors in Children's Analogical Reasoning: Implications for Learning Outcome
}

\author{
Stephen Ntim \\ PhD, M. Phil, M. A, B.Ed, Faculty of Education, Catholic University of Ghana Sunyani, Fiapre, \\ Ghana, W/A \\ Email: stephenntim58@yahoo.com/stephen.ntim@cug.edu.gh
}

\section{Mavis Okyere}

M.Phil, B.Ed, Faculty of Education, Catholic University of Ghana Sunyani, Fiapre, Ghana, W/A Email:mayawuah@yahoo.com

\begin{abstract}
This study investigated analogical errors made by children aged between 3-4, 5-7 and 9-11 years in analogical reasoning in two administrative regions of Ghana. Analyzing patterns of errors of these children in analogy formation, data in all three age groups, 3-4 years, 5-7 years and 9-11 years suggest children were more likely to make relational errors in analogies that contained more load and distraction than one-relation analogy without distraction- an indication that an additional levels of relational complexity imposes extra mental load making analogical processing more cumbersome for younger children. This finding was interpreted as corroborating what has been established in other studies that the fundamental cause of children's errors in analogy has to do with managing mental load. Children can attend to any analogy provided it is within their knowledge base and working memory capacity and not so much on age per se. Pedagogical implications of working memory resource deficits are drawn for student-centered and constructivist approaches to teaching and learning.
\end{abstract}

Keywords: Analogical Errors, Working Memory Capacity, Executive Control, Constructivists Learning.

\section{Introduction}

The ability to reason analogically is a central feature of human cognition (Gentner \& Holyoak, 1997; Hofstadter, 2001). Analogy has been defined as the transfer of a structured set of relations from a base domain to a target from which it is more or less distant. A classic example is the $A: B$ :: $C: D$ analogy (for example, dog: doghouse :: bird? solution 'Nest'. Here the 'lives in' relation must be abstracted). In other words in analogy, a solution to a problem can be used to solve a target problem (Holyoak et al., 1984). Thinking analogically constitutes a critical component in developing children's higher thinking processes because analogy becomes a strategy by which children are taught to make inferences, to extract relevant 
information from day-to-day learning experiences based on relational similarity as well as to transfer learning across different domain contexts (Halford, 1993; Holyoak, Junn \& Billman, 1984; Chen, Sanchez \& Campbell, 1997; Gentner, 1977; Goswami, 2001).

Indeed many empirical studies have been conducted to investigate the changes in the ability of analogical reasoning (Chen, Sanchez, \& Campbell, 1997; Gentner, 1988; Goswami \& Brown, 1990; Holyoak, Junn, \& Billman, 1984; Richland, Morrison, \& Holyoak, 2006; Thibaut, French, $\&$ Vezneva, 2010a). Data in most of these empirical studies underscore the fact that analogical reasoning can be found as early as in 10 month-old babies (Chen et al., 1997). The core findings in most of these studies devoted to children's analogical reasoning contrast the submission of Piaget and collaborators (1977) that it was it was not until the onset of adolescence that children consistently and successfully completed analogies.

Other researchers as Gentner and others offer a different account of the development of analogical reasoning suggesting that a 'relational shift' occurs in children's analogies through development (Gentner \& Toupin, 1986; Gentner, 1988). Due to this shift, children's analogical reasoning changes from being initially based on the surface similarity of object attributes to gradually including relational information between objects and then later on involving systems of relations. In addition, she postulates that analogical competence varies from domain to domain suggesting that the crucial constraint on analogical development is the knowledge that the child has about the relevant relations (Goswami, 1996; Gentner, 1988). Indeed, Goswami and Brown (1989) showed that if sufficiently well-known relations were used 4- and 5-year-olds could complete analogies of the kind Piaget had suggested they would fail.

Thus, children's analogical reasoning capacities improve as their knowledge of the involved relations, or their abilities to resist irrelevant information increase. Several models have been proposed in order to explain these changes which can be categorized into two subclasses: those models explaining the development of analogical reasoning as a result of the increase of children's structured knowledge about the world (Goswami, 1992) and those suggesting that the key to this development is the maturation of control processes such as working memory or executive functions (Halford, Wilson, \& Phillips, 1998; Richland et al., 2006).

Some authors characterize analogy-making as a search through a space of features and potential relations. The number of relations holding between any A:B pair is potentially large because, depending on the context, any number of different relations might be relevant (Chalmers, French, \& Hofstadter, 1992; French, 1995; Hofstadter, 1995; Mitchell, 1993). The structure of the search space and the presence or absence of competing non-analogical solutions have an effect on the search, especially for young children, who have greater difficulty handling the cognitive load associated with a more elaborate search of the space of possible solutions.

\section{Statement of Problem}

One fundamental error in literacy skills exhibited by most Ghanaian children in the primary schools, especially in the area of isomorphic problem solving, mathematical thinking and reading comprehension is that most of these children tend to focus on the superficial features rather than on the underlying relational structural properties between the source and the 
target problem. This is especially so among novice problem solvers. While good problem solvers tend to recall accurately structure of source problems, poor problem solvers on the other hand may not even notice the analogous structure in the target problem. Common error among Ghanaian primary school children is the tendency to ignore structural conditions involved in the source or target problems and hence failure to use analogy properly. Most children do not know when and how to make use of the related structural properties, and how this can be of benefit in solving problems. It is essential that in employing analogical reasoning, students (pupils) have the relevant competencies and knowledge about the rules of discourse in the domain whether mathematical or literary comprehension. Poor mathematical reasoning and less skilled reading ability especially inferential comprehension in English continue to be a hurdle for most basic school children in the public basic schools.

For example, in the general resume of the Chief Examiners report for Basic Education Certificate Examination (BECE) for 2005 and 2007 and other subsequent years, poor mathematical reasoning and English comprehension have consistently been identified as the bane of most Ghanaian children (Chief Examiners' Report, April 2005, p. 3; Chief Examiners' Report, 2007, p. 12) This problem among many primary school children in Ghana notwithstanding, not much (if any) empirical research have been conducted to find out the root cause of analogical reasoning errors as ways to help classroom teachers to enhance effective teaching in problem solving, mathematical reasoning and reading comprehension. This research is meant to fill the gap in the literature on children's errors in analogical reasoning in Ghana.

\section{Research Objectives}

Consequent on the above defined problem, the subsequent two objectives that guided this study were:

1) To investigate the underlying pattern of analogical errors of these children through featural distraction.

2) To assess whether or not surface analogical errors are age-related.

\section{Research Questions}

The key questions then that this study investigated were:

1) What are the underlying patterns of analogical errors of featural distraction of these children?

2) Are analogical errors of surface similarity age-related or dependent on other factors than age?

\section{Significance of the Study}

The findings of this study will help to underscore some of the precursors to conventional literacy that is linked to concept formation in mathematical and literal inferential reasoning for which reason it would be beneficial to basic school teachers. Ability to draw connections between concepts, problems, or representations through analogy thinking is crucial to mathematical proficiency and reading comprehension as well. Consequently, the outcome of this paper will help teachers to understand the psychological underpinnings of children's poor 
performance in analogical reasoning and general problem solving. Besides, this study is significant because of the reported crisis of reading and numeracy achievement in most public basic schools in Ghana compared to private schools. For example, Reading achievement levels as measured by the Government-administered Criterion Referenced Test in 2000 indicate that fewer than $10 \%$ of the school children at primary level six are able to read with grade level mastery. It is also reported that some parts of Africa, such as Malawi and Zambia, over a third of grade 6 students failed to acquire the most basic literacy skills.

\section{Literature Review}

The capacity to think logically and solve problems in new situations is believed to be central to theories of human intelligence often referred to as 'fluid' reasoning (Carrol, 1997; Cattell 1987; Gray et al., 2003; Horn, 1988). Indeed, this ability to think has been identified as leading indicator of changes in crystallized abilities (McArdle, 2001) as well as changes in academic achievement factor especially in quantitative ability, academic knowledge (Ferrer \& McArdle, 2004), and reading (Ferrer et al, 2007). One form of this reasoning is relational reasoning: that is, the ability to find correspondences between the structures of distinct mental representations. Analogical reasoning may be considered a specialized form of relational reasoning, one that entails abstracting a higher-order relation between a familiar representation (the base) and mapping it to a novel representation (the target) (Gentner, 1988; Goswami \& Brown, 1989).

The most rudimentary form of analogical reasoning is captured by propositional analogy problems (e.g., car is to road as boat is to...?) In these problems, it is necessary to not only abstract the higher-order relationship between the base items (car "moves on" road) but also map this higher-order relationship to the target pair (boat "moves on"?) in order to fill in the missing piece (water).

Piaget argued that, before the stage of formal operations, around age 11, children do not possess the cognitive capacity to represent the necessary relations needed to perform classical analogy problems (Inhelder \& Piaget, 1958). When Piaget and his colleagues presented children with pictorial problems of the form 'A:B::C:D' and asked them to find the $D$ term in a pictorial set, he found that children often relied on lower-order relations to solve the problems, choosing items that were associated with or looked like the $\mathrm{C}$ item (Piaget et al., 1977). Sternberg and colleagues found similar limitations in young children's analogical reasoning, observing an over-reliance on lower-order relations during analogical problem solving (Sternberg \& Downing, 1982; Sternberg \& Nigro, 1980).

More recent investigations have revealed, however, that children can effectively reason by analogy at young ages. Children as young as 3 years of age have been found to perform successfully on classical 'A:B :: $C: D$ ' analogies as long as they are familiar with the relevant relations necessary to solve the problems (Goswami \& Brown, 1989). Numerous other studies have demonstrated children's ability to solve problems through analogical reasoning (Holyoak et al., 1984; Pierce \& Gholson, 1994; Richland et al., 2006; Singer-Freeman \& Goswami, 2001; Tunteler \& Resing, 2002), and prominent analogical theorists have suggested that analogy is an essential means by which cognition develops (Goswami \& Brown, 1989).

In the developmental literature, many attempts have been made to study those factors that are likely to explain children's difficulties in solving analogies especially regarding patterns of 
errors exhibited by most children. Various views have been offered. One important view is that children's failure to solve analogies especially when they make consistent errors is because they lack the necessary knowledge to understand the relations involved in the analogies. A second hypothesis explains young children's inabilities and consistent errors in analogy by their less developed executive functions. This latter view for example was tested in the study by (Thibaut, French \& Vezneva, 2010). These authors manipulated the nature and number of perceptual distractors in an $A: B$ :: C:D paradigm. A number of authors who have studied the developmental mechanisms of analogy-making have also suggested that a gradual progressive improvement of various processing capacities -in particular, an increase ability to cope with cognitive load-is responsible for improved analogy-making skills with age. The recent work of Richland, Morrison and Holyoak are in this area of cognitive processing capacities (Halford, 1993; Richland, Morrison, \& Holyoak, 2006)

Executive functions have been invoked to explain the development of analogy making, multifaceted ability. Crucially, analogy making involves selecting the information that is relevant to the analogy and rejecting the information that is not. For example, if $A$ and $B$ are a bird and a nest, respectively, and $\mathrm{C}$ is a dog, then D should be a doghouse. Distractors (e.g., bones, a cat), even though they are highly thematically or taxonomically related to $C$ (the dog), must be actively rejected as solutions to the analogy. Halford, Wilson, and Phillips (1998) argued that one fundamental constraint acting on cognitive development is the maximum relational complexity, defined as "the number of related dimensions or sources of variations" (p. 803) that can be processed in parallel in working memory. This number increases with age. However, this linear trend has been contested (Goswami, 1998; Rattermann \& Gentner, 1998). In Halford and colleagues' view, maturational changes in processing capacity represent the major impetus of development.

Richland and colleagues (2006) in a similar way have also argued that children's analogy making of specific abilities is tied to executive functions. This link to executive functions has to do particularly to their ability to integrate multiple relations and to "inhibit tendencies to respond on the basis of competing superficial similarities" (p. 253). This executive function approach to children's development of analogies contrasts with other views of children's capacities in analogy making. Other authors have emphasized the role of domain knowledge, implying that that increasing knowledge about relations in one conceptual domain will increase analogy making in the target domain (cf. Goswami \& Brown, 1990; Vosniadou, 1995). According to Goswami (1992), analogical reasoning is already available during infancy (see Chen, Sanchez, \& Campbell, 1997). According to this account it is only the lack of knowledge in the conceptual domains involved that prevents children from deriving the correct analogies.

Gentner (1988); Gentner and Rattermann (1991); and Rattermann and Gentner (1998) suggested that the "relational shift" occurs in many domains during development even though this shift does not occur at the same time for all domains. It is defined as a shift from early attention to featural similarities to later attention to common relational structures. After the shift, children will primarily succeed in analogical reasoning tasks because they are able to reason on the basis of relational features. Even though the distinction between attributes and relations is far from clear and, at the very least, is highly context dependent (Chalmers, French, \& Hofstadter, 1992; French, 1995; Mitchell \& Hofstadter, 1990) 


\section{Present Study}

In this study, we investigated some errors made by children aged between 3-4, 5-7 and 9-11 years in analogical reasoning specifically of the propositional type $A: B:: C:$ ? for example, LAWYER: CLIENT::DOCTOR:? with some distractions. The specific research questions were: a) What are the underlying patterns of analogical errors of featural distraction of these children?

b) Are analogical errors of surface similarity age-related or dependent on other factors than age? Our expectation is that answers to these two questions will help to provide some psychological insights into the causes behind the errors that many children make in problem solving strategies. Such knowledge will help teachers to anticipate children's/pupils/students errors bearing in mind the root cause of such misconceptions so that they can either preempt these in instruction or include questions that might surface in such errors in assessment for learning.

\section{Research Methodology \\ Sample}

This study used the purposive experimental sampling design from an estimated one hundred and sixty (160) children between the ages of 3-11 randomly chosen from four kindergarten and four (4) primary schools in two out of the ten (10) administrative regions of Ghana: Ashanti: eighty (80) children from two (2) kindergarten and two (2) primary schools in the Kumasi Metropolis and Nkawie districts and in the Brong Ahafo region: eighty (80)) from another two

(2) kindergartens and two primary schools from Berekum and the Sunyani Municipalities. The various age groups were in the following categories: 3-4 year olds were sixty (60), 5-8 year olds, seventy (70) and 9-11 year olds, thirty (30). In a data not tabled here an estimated $50 \%$ of the sample was male and the rest were females.

\section{Materials and Design}

The materials for this task were the A:B: : C: ?. Participants were presented with saw, two or three analogues of a source and target of the $A: B:: C:$ ? for them to figure out the relations between them. In this experiment the number of 9-11 years was intentionally reduced to about half of the 3-4 years and 5-8 years since our interest principally was to find out the causes of analogical errors of these much younger children especially in the area of errors of surface similarity which is perceived to be typical of little children. Again we wanted also to know whether these little children had relational knowledge of the 16 relations used in the analogies with distractors and could avoid making surface errors.

\section{Experiment}

In this experiment, we used list stimuli to build analogies. The purpose of this experiment was to test our two research questions: a) what are the underlying patterns of analogical errors of featural distraction of these selected children? and b) Are analogical errors of surface similarity age-related?

\section{Experimental Task and Control}

Participants saw 16 sets of analogies in which the level of relational complexity and the presence or absence of a featural distractor were manipulated. Each participant saw five analogy sets in each condition: one relation/distractor, one relation/ no distractor, two 
relations/distractor, and two relations/no distractor. The content of the analogy sets was counterbalanced across four versions in this Experiment.

\section{Ensuring Relational Knowledge of Younger Children}

To make sure that the younger children (3-and 4-year-olds) knew the relations and the relational words used to describe the source relations in the 16 analogies used in this Experiment, they were asked to identify a relation and were asked which of the two analogies given showed that relation. So a task was constructed to require these children to choose between two analogy alternatives. Two analogies were aligned on each page with a relation written above them. The relation was read by the experimenter to the children. A total of 16 pairs were constructed so that each participant made judgments about all 16 relations. The placement of the correct analogy was varied randomly between the left and right sides. The one hundred and sixty participants (160) were exposed to initial explanation of relational knowledge.

\begin{tabular}{|c|c|c|c|c|c|}
\hline A & B & C & D (Target) & $\begin{array}{l}\text { Semantic } \\
\text { Distractor }\end{array}$ & Relation \\
\hline \multicolumn{7}{|c|}{ Practice trials } \\
\hline Wolf & Meat & Goat & Grass & Horns & Eat \\
\hline Child & Foot & Elephant & Paw & Giraffe & Part of \\
\hline
\end{tabular}

Figure 1

On the test problems (presented randomly) the experimenter verbally explained the relevant relation between the source and the target. For example, the experimenter described the agent engaged in the relevant relation in the source: wolf (agent): meat (object) so goat (agent):? explaining that the relation between the analogy is 'eat' with a semantic distractor of 'horns' Similar explanation was given in the second set of analogies where the experimenter explained the relation between $A: B$ and $C: D$ as 'part of' so what is like when given a ternary analogy as Child: foot: elephant:?

Further explanation was given to children as follows: 'sometimes what is happening will have two parts, like the wolf and meat, and sometimes there will be three parts just like child: foot: elephant? Even though they look different (experimenter pointed to each) but try in each case to

figure out what is 'common' or 'the same' or 'is like' in spite of the differences. The researcher repeated the instruction if necessary, to ensure the child understands the task. 
INTERNATIONAL JOURNAL OF ACADEMIC RESEARCH IN PSYCHOLOGY

Vol. 2, No. 1, 2015, E-ISSN: 2312-1882 ๔ 2015 KWP

Results

Table 1: Mean Scores of Number of Errors Made by the Different Age Groups

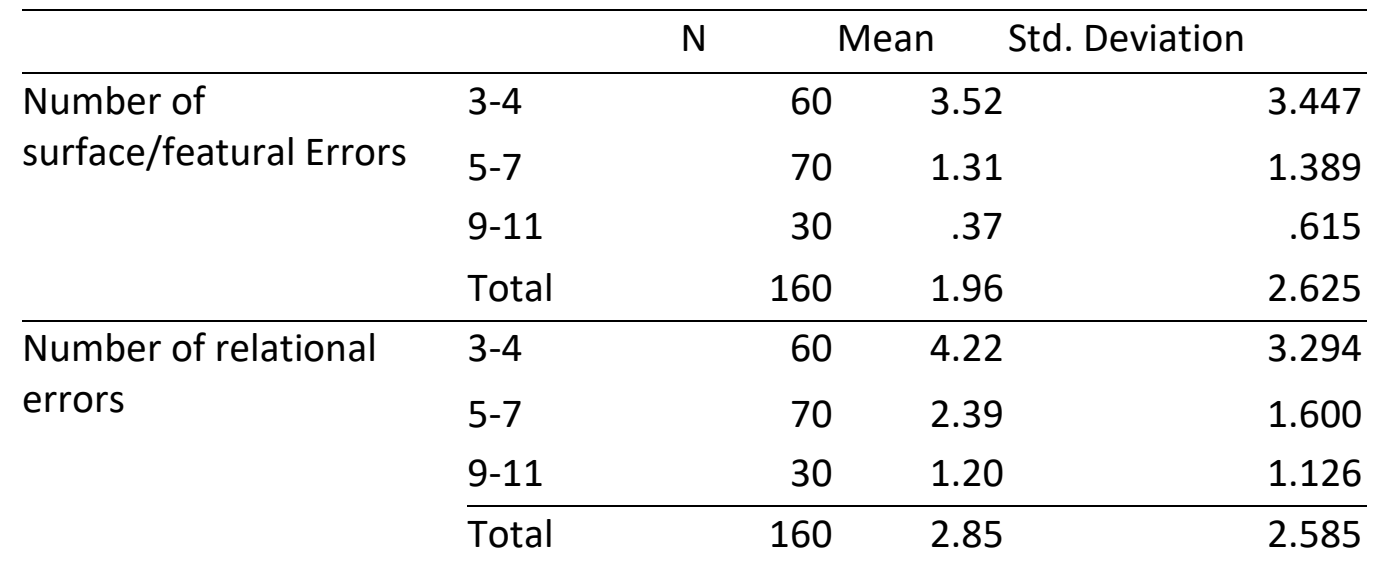

The over-all results for the three groups on surface errors and relational errors as in Table 1, shows that number of errors made was age dependent. The results show that the younger group of children 3-4 year olds had the largest number of errors in both featural and relational errors. Their mean score on the errors were $(M=3.52, S D=3.447)$ and $(M=4.22, S D=3.294)$ respectively for surface/featural errors and relational error. The older group, 9-11 year olds had mean score of $(M=0.37, S D=0.615)$ and $(M=1.2, S D=1.126)$ respectively for surface/featural and relational errors an indication that they had the least number of errors. To test whether these differences in the mean scores of the number of errors made by the different age groups were statistically significant, one-way analysis of variance (ANOVA) was used and the result is presented in Table 2

Table 2: ANOVA Test on the Surface/Featural and Relational Errors for the Three Age Groups

\begin{tabular}{|c|c|c|c|c|c|c|}
\hline & \multicolumn{2}{|c|}{ Sum of Squares } & \multicolumn{3}{|c|}{ Mean Square } & \multirow[b]{2}{*}{ Sig. } \\
\hline & & & Df & & $F$ & \\
\hline Number of & Between & & 2 & 125.370 & 23.293 & .000 \\
\hline surface/featura & Groups & 250.739 & & & & \\
\hline I Errors & Within & & 157 & 5.382 & & \\
\hline - & Total & $\begin{array}{l}845.036 \\
1095.775\end{array}$ & 159 & & & \\
\hline Number of & Between & & 2 & 104.415 & 19.206 & .000 \\
\hline $\begin{array}{l}\text { relational } \\
\text { errors }\end{array}$ & $\begin{array}{l}\text { Grouns } \\
\text { Within }\end{array}$ & 208.831 & 157 & 5.437 & & \\
\hline- & Total & $\begin{array}{l}853.569 \\
1062.400\end{array}$ & 159 & & & \\
\hline
\end{tabular}

The ANOVA test revealed that significant differences exist between the different age groups in terms of the number surface/featural errors and relational errors made. To find out the age groups which differ on the two variables a post-hoc test was conducted. The test on equality of variance as shown in Table 3 shows that there are statistically significant differences in variances of the three age groups on the two variables. 
Table 3: Test of Homogeneity of Variances

\begin{tabular}{lcccc}
\hline \multicolumn{2}{c}{ Levene } & & & \\
& Statistic & df1 & df2 & Sig. \\
\hline $\begin{array}{l}\text { Number of surface/featural } \\
\text { Errors }\end{array}$ & 62.171 & 2 & 157.000 \\
\hline Number of relational errors & 26.409 & 2 & & \\
\hline
\end{tabular}

That the variances of the age groups on surface and relational errors were significantly different. The Game-Howell's Pos Hoc test was therefore used to find the differences in the mean errors of the three age groups on the two variables. The result is shown in table 4.

The result of the Pos-Hoc test shows that the younger age group 3-4 year olds had mean scores greater than the two other groups on the two variables. On surface/featural errors the mean differences between this year group and the 5-7 and 9-11years were 2.202 and 3.150 respectively. Also, on the relational error variable the mean difference between the year groups were respectively 1.831 and 3.017 .

Table 4: Comparisons of the three age groups on the two variables

\begin{tabular}{lllllrl}
\hline \multirow{2}{*}{$\begin{array}{l}\text { Dependent Variable } \\
\text { Number of surface/featural }\end{array}$} & $\begin{array}{l}\text { (I) age of } \\
\text { participant }\end{array}$ & $\begin{array}{l}\text { (J) age of } \\
\text { participant }\end{array}$ & $\begin{array}{l}\text { Mean } \\
\text { Difference (I-J) Std. Error }\end{array}$ & \multicolumn{2}{c}{ Sig. } \\
\hline Errors & $3-4$ & $5-7$ & $2.202^{*}$ & .475 & .000 \\
& $3-4$ & $9-11$ & $3.150^{*}$ & & .459 & .000 \\
& $5-7$ & $9-11$ & & $.948^{*}$ & .200 & .000 \\
\hline Number of relational errors & $3-4$ & $5-7$ & & $1.831^{*}$ & .466 & .001 \\
$3-4$ & & $9-11$ & $3.017^{*}$ & .472 & .000 \\
$5-7$ & & $9-11$ & & $1.186^{*}$ & .281 & .000 \\
\hline
\end{tabular}

The mean difference is significant at the 0.05 level.

\section{Discussion}

Results of this experiment are consistent with other research studies in the following three areas: a) effect of age as a factor on participants' error responses; b) there was main effect of relational complexity and distraction on children's error and c) data supporting other studies that besides age, there are other factors that explain the causes of children's analogical errors and set limits to their analogical reasoning: for example, relational complexity and distraction can increase mental load especially for much younger children, if the target and the base analogues are not within their knowledge base. Thus, as per the data of this experiment, the effect of age in relation to accuracy of responses in analogical reasoning is still paramount.

This is evident when we run the Games-Howell multiple comparisons between the different age groups. However, there is no suggestion from this experiment that this age factor variable per se is independent. The measure that examined the pattern of errors seems to suggest that the age factor is almost always related to relational complexity: the longer the analogy (in terms of length), the less likely it was for younger ones to have accurate responses and 
the shorter the analogy, the better the responses of these younger children. Thus younger children seem to have challenges with mental load when they simultaneously have to process longer analogies and distractions and these challenges seem to precipitate the consistent pattern of errors as this experiment revealed. Thus, younger children's performance was impaired and more errors made when surface/featural competitions were added. Most errors were on the surface match with a ternary relation and distractions rather than simply with surface matches with the A or B term. Again this finding is consistent with other recent studies such as Thibaut, French and Vezneva (2010). When these authors asked younger children to justify the reasons for the choices they made (mostly the erroneous ones), the answers they gave could not be taken as justifying analogical reasoning.

The pattern of analogical errors as per the findings of this study is underscored mostly by distractions and the length of the analogy whether it is binary or ternary. This means that when the processing load of analogies is within the scope, mental capability as well as the understanding of children, they can conveniently see the link between base analogue and target analogue. This surface/featural errors support the submission of Goswami and Brown (1989), Goswami $(1992,2001)$ and Goswami, Leevers, and Wheelright (1998). These authors in proposing the relational primacy hypothesis make the claim that that analogical reasoning is fundamentally available as a capacity from early infancy. However, children's analogical performance increases with age due to what these authors refer to as 'accretion of knowledge about relevant relations.

What these data seem to suggest is that the number one underlying causes of children's analogical errors has to do with a continuum of executive control especially in children's searching the solution space of analogical problem. For much younger children, there appears to be a lack of control. In this lack of control, the lack of inhibition appears to play a very significant but certainly not an exclusive role since the age-related factor is still crucial (cf. Thibaut, French \& Vezneva, 2010). Thus greater executive function skills both composite and inhibitory control as well as vocabulary knowledge are all predicting factors that explain whether or not children can succeed in analogical reasoning. In other words, knowledge is a prerequisite in analogy performance, this notwithstanding, a strong executive-functioning resources at early childhood and basic school are related to long-term gains in fundamental reasoning skills (Lindsey \& Burchinal, 2012).

Besides, the findings of this study as indicated in the patterns of errors showed that when children across the three age groups responded on the basis of relational correspondences, there was competition with tendencies to respond more on the basis of superficial surface or semantic similarities between individual objects. This suggests the need for inhibitory control in working memory when relational and more superficial responses conflict, giving support to studies that see inhibitory control as a factor in the development of analogical reasoning in children (Gentner \& Toupin, 1986; Morrison et al., 2004; Viskontas et al., 2004).

\section{Educational Implications of Findings for Learning Outcome}

There are three key findings in this research: a) First the effect of age on children's pattern of errors is still critical, especially for much younger children, b) the main effect of relational complexity and distraction on children's errors and c) other factors than age such as cognitive load especially when there is divergence or structural differences between base analogue and 
target analogue. These findings reinforce those studies that aim at predicting learning outcomes by considering the capabilities and limitations of the human cognitive architecture. For example, Cognitive Load Theory (CLT), put forward by Sweller in 1988, maintains that cognitive load should be controlled so that meaningful learning can occur in the interactions of all elements. As working memory is limited in capacity (Miller, 1956) and duration (Peterson \& Peterson, 1959), all instructional material imposes a working memory or cognitive load, and that cognitive load can be divided into extraneous cognitive load, intrinsic cognitive load, and germane cognitive load.

The first assumption of the cognitive load, which is a main assumption for many cognitive theories summarizes that human working memory, the cognitive subsystem for processing current information, is limited in its capacity for processing. The second assumption it offers is that meaningful learning requires active processing of information by the learner. Active processing in turn requires cognitive processes such as children focusing the attention on the relevant learning content (selection), mentally organizing information in a coherent way (organization) and integrating new information with existing knowledge (integration). So for example in the typical propositional analogies as presented in this study there were three principles of cognition: apprehension of experience, education of relations and education of correlates. How can we understand these three principles of cognition? Consider the analogy A:B :: C:? for example, LAWYER: CLIENT::DOCTOR:? Apprehension of experience refers to children encoding (perceiving and understanding each of the given terms of the analogy. Education of relations refers to the inference between the first two analogies LAWYER and CLIENT. Education of correlates is the application of inference by children to a new domain here inferring lawyer to a client and doctor to a patient.

By all accounts then, learning cognitively speaking is a complex task that requires a student to use and apply a range of cognitive skills. A student's ability to retain information while performing concurrent processing, often referred to as working memory (WM), is critical to the acquisition of increasingly more complex knowledge and skills as evidenced from this study. Distraction and more complex analogies became difficult for younger children in this study and their consistent errors indicated some constraint on the working memory and attention. It is in this context that cognitive approaches to learning often link Working Memory resources to successful learning and student academic achievement. Consequently, there is an inextricable link between student learning and the cognitive processes required to acquire new knowledge with a specific focus on WM and attention. It is in this context that the constructivist view effective learning as coming from the students: students must construct knowledge in their own minds and must individually discover and transform complex information, checking new information against old rules and revising rules when they are no longerworking.

In short, as corroborated in this experimental study, children's ability to master the content of the task (analogies) assigned them largely depended on their ability to successfully process information in WM. While, some children were able to do so successfully, others were not because information that they were trying to process overloads their WM and when this takes place learning and understanding are negatively affected. For example, attention is also linked to the WM. It is significantly related to and influences WM particularly when children in this study were asked to encode information in the source and make relations between 
source analogue and target and provide the answer. They were distracted especially in the ternary analogies. There are many factors that control attention: motivation, anxiety, fatigue, fear of giving the wrong answer etc. Results of several recent studies show that attention significantly influences WM, particularly when students must encode information (e.g., when a student is listening to a lesson on various cloud formations). Attention controls the amount of time a student needs to maintain information in WM, especially in visual WM. If, for any reason, a students' attention is disturbed, his or her opportunity to learn is diminished. Furthermore, if a student cannot control his attention, interfering information will not be filtered out and learning will also be adversely affected. In sum, the inability to regulate attention is directly related to student academic performance.

This argument of the importance of WMC (working memory capacity) ties in with one of the fundamental key concepts that underlie the constructivists approach to learning, namely, the zone of proximal development which goes back to Vygostky (1978) that children work within their zone of proximal development when they are engaged in tasks they could not do alone but can do with the assistance of peers or adults. For example, when younger children were asked in this study to justify their reasons for their analogical errors, they could not provide any tangible reasons. It is in this respect that there is the need for children to get cognitive apprenticeship, a process by which a learner gradually acquires expertise through interaction with an expert. This leads to mediated learning: an approach in which the teacher guides students by means of scaffolding (teacher providing more gradual structure and then gradually turns the responsibility over to students.

Based on the findings of this study then, it is crucial especially when teaching at the basic level of education to help learners maximize their working memory resources (Clark et al. 2003; Xiaoning, 2014). Many researches employ various mechanisms of maximizing leaners to manage working memory resources to enhance learning. For example, Lee et al (2006) holds employing graphs, Kester et al. (2006) proposes constructing just-in-time model to present information. Mayer \& Moreno (2002) suggests adopting multi presentation effect, congruity effect, coherence effect and redundancy effect in the multimedia instructional design. Clark et al (2003) make the submission that multi-presentation effect, dual-code effect, split-attention effect, modality effect, redundancy effect, animations and element interactivity may reduce extraneous load. As for reducing intrinsic load, Gerets et al. (2004) follows partial-whole order while Van Merrienboer (2002) presents teaching information by simplifying modules of tasks and steps. Lee et al. (2006), Moreno and Valdez (2005) emphasize the need to display complex information by segmentation and Renkl (2004) proposes the use of fading solutions steps to present incomplete examples. Lee et al. (2006) holds that when the complexity of knowledge lowers, lowering extraneous load and increasing germane load merely works for learners with lower prior knowledge. The more complex the knowledge, the richer prior knowledge the learner has contributed to form a new schema and thus lowering the intrinsic load. In terms of increasing germane load, Paas et al (1994); Sweller (1998) provide working examples, and Moreno and Mayer (2000, 2004) promote individual learning, Seufert and Brinken (2006), Moreno and Mayer (2007) see the need to conduct guidance teaching, Moreno and Mayer (2005); Hattie and Timperley (2007) organize feedback teaching, Moreno and Mayer (2007); Moreno and Valdez (2005) undertake reflection teaching. All these efforts have gained remarkable achievements in managing WMC overloads. 
Recent research in learning disability has also underscored Working memory to be a strong predictor of both mathematical (Toll, Van der Ven, Kroesbergen, \& Van Luit, 2011) and reading difficulties (Horowitz-Kraus, 2014), and therefore it is considered to be the requisite basis for pedagogical intervention to enhance performance. The development of the working memory system underlies performance in both math and reading (Jerman, Reynolds, \& Swanson, 2012). Researchers have found differences between individuals with and without math difficulties in spatial aspects of working memory (Mammarella, Lucangeli, \& Cornoldi, 2010; Passolunghi \& Mammarella, 2012), as well as between individuals with and without reading difficulties in the efficiency of encoding and rehearsal mechanisms (Oyler, Obrzut, \& Asbjornsen, 2012) - both of which involve the working memory system. Given the problems that individuals with LDs often experience with the working memory system (Hallahan, Pullen, \& Ward, 2013), it is important for educators to plan and implement lessons that reduce the germane and extraneous load (De Weerdt, Desoete, \& Roeyers, 2012).

When it comes to interventions aimed at improving working memory (and reducing the cognitive load) for individuals with LDs, there are a few main approaches that are used. Researchers have focussed on the explicit teaching of strategies that individuals can use to reduce the germane load of tasks, and therefore reduce the load on working memory. Other research has been conducted that examines the capacity of working memory, and the potential for this system to be improved or "trained" (e.g., Melby-Lervag \& Hulme, 2013). Finally, there are accommodations that educators can make for students with LDs that reduce the extraneous load in tasks at school. Again the findings from this study confirm other empirical research in educational technology and development that highlights the link between germane cognitive load and learning performance. Metaphorical interface in a webbased study enhanced learners' germane cognitive load and learning performance more than it was for non- metaphorical interface (cf. Cheon \& Crane, 2012). In other words, the more information was encapsulated in schema-based or metaphorical format, the less the constraints on learners executive functions. This implies that in most cases children are more likely to make errors in analogical reasoning, the more complex the load.

\section{Conclusion}

The two research questions that guided this paper were: a) What are the underlying patterns of analogical errors of featural distraction of these children? and b)Are analogical errors of surface similarity age-related or dependent on other factors than age? In the analysis of the pattern of errors of these children in analogy formation, the data suggest that in all the three age groups, 3-4 years, 5-7 years and 9-11 years, children were more likely to make relational errors with two-relation analogy with distractors than one-relation analogy without distraction- an indication that an additional levels of relational complexity imposes an extra mental load making analogical processing more cumbersome, especially for much younger children. These findings provide support for the relational primacy hypothesis that in analogical reasoning, children have the capability to attend to and make mapping relations. However, they are less likely to overcome misleading object surface similarity and are also less likely to maintain relational structure especially when an additional level of complexity is imposed.

The implication here as per the findings of this paper is that the root cause of many children's analogical errors is not simply age-specific, but also executive controls as well as inhibitory factors do combine with age to constrain analogical reasoning giving some weight to the 
additvity hypothesis theory of cognitive load (Pass et al, 2003). The instructional implication here is that to make teaching more efficient and learning more enhanced, instructional load (also called germane load) as much as possible need to be made less loaded for most children. This is especially so in problem solving, mathematical reasoning and reading comprehension during the early stages of learning. Prerequisite knowledge (generally referred to by Ghanaian basic school teachers as 'RPK'- relevant previous knowledge) or domain specific knowledge alone is not sufficient to enhance children's problem solving skills. For example, analogies can be used to make learning relevant and activate prior knowledge. Like advance organizers, the use of explanatory analogies can contribute to an understanding of lessons or text. They help students learn new information by relating it to concepts they already know. However it is also important that analogies are thoroughly familiar to learners than they relate in any direct way to the concepts being taught since poor use of analogies can rather inhibit learning.

One significant finding from this study is children's inability to cope with relational complexity of ternary analogies. The consistent errors in all groups on ternary analogies with distractions and complex relations were interpreted as working memory overloads. These working memory resource deficits were interpreted to have implications for learning outcome especially in the area of student-centered learning and constructivists' approaches to learning specifically in cognitive apprenticeship, mediated learning and scaffolding. So besides emphasizing prerequisites knowledge as in mastery learning, teachers also need to pay attention to balancing inhibitory control in working memory and relational representation of children's cognitive processes as well, which de facto implies the need for student-centered approach to learning.

\section{References}

Andrews, G., \& Halford, G. S. (2002). A cognitive complexity metric applied to cognitive development. Cognitive Psychology, 45, 153-219.

Carroll, J. (1997). Psychometrics, intelligence, and public perception. Intelligence 24 (1), 2552. Cattell, R. B. (1987). Intelligence: Its structure, growth and action. Amsterdam, North-Holland Publishing Co.

Chalmers, D. J., French, R. M., \& Hofstadter, D. R. (1992). High-level perception, representation, and analogy: A critique of artificial intelligence methodology. Journal of Experimental and Theoretical and Artificial Intelligence, 4, 185-211

Chen, Z., Sanchez, R., \& Campbell, T. (1997). From beyond to within their grasp: Analogical problem solving in10- and 13-month-olds. Developmental Psychology, 33, 790-801.

Cheon, J., \& Crane, M. M. (2012). The effects of metaphorical interface on germane cognitive load in web-based instruction. Educational Technology Research and Development. 60(3), 399- 420.

Chief Examiners Report. (2005): Ghana Education Service, Ministry of Education, Ghana.

Chief Examiners Report. (2007): Ghana Education Service, Minstry of Education, Ghana.

Clark, R., Nguyen, F., \& Sweller, J. (2003). Efficiency in learning: Evidence-based guidelines to manage cognitive load. Pfeiffer Progress: San Francisco.

De Weerdt, F., Desoete, A., \& Roeyers, H., (2012). Working memory in children with reading disabilities and/or mathematical disabilities. Journal of Learning Disabilities, 46, $461-$ 472. 
Ferrer, E., \& McArdle, J. J. (2004). An experimental analysis of dynamic hypotheses about cognitive abilities and achievement from childhood to early adulthood. Developmental. Psychology. 40, 935-952.

Ferrer, E., McArdle, J. J., Shawitz, B. A., Holahan, J. N., Marchione, K., \& Shawitz, S. E. (2007). Longitudinal models of developmental dynamics between reading and cognition from childhood to adolescence. Developmental . Psychology. 43, 1460-1473.

French, R. M. (1995). The subtlety of sameness . Cambridge, MA: MIT Press

Gentner, D. (1977). If a tree had a knee, where would it be? Children's performance on simple spatial metaphors. Papers and Reports on Child Language Development, 13, 157-164.

Gentner, D. (1988). Metaphor as structure mapping: The relational shift. Child Development, 59, 47-59.

Gentner, D., \& Holyoak, K. J. (1997). Reasoning and learning by analogy: Introduction. American Psychologist, 52, 32-34.

Gentner, D., \& Rattermann, M. J. (1991). Language and the career of similarity. In S. A. Gelman \& P. Bymes (Eds). Perspectives on thought and language interrelations in development. (pp.225-277).London: Cambridge University Press.

Gentner, D., \& Toupin, C. (1986). Systematicity and surface similarity in the development of analogy.Cognitive Science, 10, 277-300.

Gerets, P., Scheiter, K., \& Catrambone, R. (2004). Designing instructional examples to reduce intrinsic cognitive load: Molar versus modular presentation of solution procedures. Instructional Science, (32), 33-58.

Goswami, U. (1992). Analogical reasoning in children. Hillsdale, NJ: Lawrence Erlbaum.

Goswami, U. (1996). Analogical reasoning and cognitive development. Advances in Child Development and Behaviour, 26, 91-138.

Goswami, U. (1998). Is relational complexity a useful metric for cognitive development? Behavioral and Brain Sciences, 21, 838-839

Goswami, U. (2001). Analogical reasoning in children. In D. Gentner, K. J. Holyoak, \& B. N. Kokinov (Eds.). The analogical mind: Perspectives from cognitive science (pp. 437470). Cambridge, MA: MIT Press.

Goswami, U., \& Brown, A. L. (1990). Higher-order structure and relational reasoning: Contrasting analogical and thematic relations. Cognition, 36, 207-226.

Goswami, U., \& Brown, A. L. (1989). Melting chocolate and melting snowmen: Analogical reasoning and causal relations. Cognition, 35, 69-95.

Goswami, U., Leevers, H., Pressley, S., \& Wheelwright, S. (1998). Causal reasoning about pairs of relations and analogical reasoning in young children. British Journal of Developmental Psychology, 16, 553-569.

Gray, J. R., Chabris, C. F., and Braver, T. S. (2003). Neural mechanisms of general fluid intelligence. Nat. Neurosci. 6, 316-322.

Halford, G. S. (1993). Children's understanding: The development of mental models. Hillsdale, NJ: Lawrence Erlbaum.

Halford, G. S., Wilson, W. H., \& Phillips, S. (1998). Processing capacity defined by relational complexity: Implications for comparative, developmental, and cognitive psychology. Behavioral and Brain Sciences, 21, 803-864.

Hallahan, D. P., Pullen, P. C., \& Ward, D. (2013). A brief history of the field of learning disabilities. In H. L. Swanson, K. Harris, \& S. Graham (Eds.). Handbook of learning disabilities, (15-32). New York: Guilford Press. 
Hofstadter, D. R. (2001). Analogy as the Core of Cognition. In D. Gentner, K.J. Holyoak, and B.N. Kokinov (Eds.). The analogical mind: Perspectives from cognitive science ( $\mathrm{pp}$ 499538). Cambridge MA: MIT Press.

Hofstadter, D. R. (1995). On seeing A's and seeing As. Stanford Humanities Review 4/2 pp.109-121.

Holyoak, K. J., Junn, E. N., \& Billman, D. (1984). Development of analogical problem-solving skill. Child Development, 55, 2042-2055

Horn, J. L. (1988). Thinking about human abilities. In, J. R. Nesselroade and R. B. Catell, (Eds). Handbook of multivariate experimental psychology (pp. 645-685) New York, NY, Academic Press.

Horowitz-Kraus, T. (2014). Pinpointing the deficit in executive functions in adolescents with dyslexia performing the Wisconsin card sorting test: An ERP study. Journal of Learning Disabilities, 47, 208-223.

Inhelder, B., \& Piaget, J. (1958). The growth of logical thinking from childhood to adolescence: An essay on the construction of formal operational structures. New York, NY, Basic Books.

Jerman, O., Reynolds, C., \& Swanson, H. L. (2012). Does growth in working memory span or executive processes predict growth in reading and math in children with reading disabilities? Learning Disability Quarterly, 35,144-157.

Lee, H.-J., Plass, J. L., \& Homer, B. D. (2006). Optimizing cognitive load for learning from computer-based science simulations. Journal of Educational Psychology, 98(4), 902913.

Mammarella, I. C., Lucangeli, D., \& Cornoldi, C. (2010). Spatial working memory and arithmetic deficits in children with nonverbal learning difficulties. Journal of Learning Disabilities, 43, 455-468.

Mayer, R. E., \& Moreno, R. (2003). Nine ways to reduce cognitive load in multimedia learning. Educational Psychologist, (38), 43-52.

McArdle, J. J. (2001). A latent difference score approach to longitudinal dynamic structural analysis. In R. Cudeck,S. D. Toit and D. Sörbom, (Eds.) Structural equation modeling: Present and future. A festschrift in honor of Karl Jöreskog (p.342-380) Lincolnwood, IL, Scientific Software International.

Melby-Lervag, M., \& Hulme, C. (2013). Is working memory training effective? A meta-analytic review. Developmental Psychology, 49, 270-291.

Miller, G. A. (1956). The magic number seven plus or minus two: Some limits on our capacity for processing information. Psychological Review, (63), 81-97

Mitchell, M. (1993). Analogy-making as perception. Cambridge, MA: The MIT Press.

Mitchell, M., \& Hofstadter, D. R. (1990). The emergence of understanding in a computer model of concepts and analogy-making. Physica D, 42, 322-334

Moreno, R., \& Mayer, R. E. (2000). A coherence effect in multimedia learning: The case of minimizing irrelevant sounds in the design of multimedia instructional message. Journal of Educational Psychology, 92(1), 117-125.

Moreno, R., \& Mayer, R. E. (2004). Personalized messages that promote science learning in virtual environments. Journal of Educational Psychology, 96, 165-173.

Moreno, R., \& Mayer, R. E. (2005). Role of guidance, reflection, and interactivity in an agentbased multimedia game. Journal of Educational Psychology, 97, 117-128.

Moreno, R., \& Mayer, R. (2007). Interactive multimodal learning environments. Educational Psychology Review. Vol. 19, (3) 309-326 
Moreno, R., \& Valdez, A. (2005). Cognitive load and learning effects of having students organizing pictures and words in multimedia environments: The role of student interactivity and feedback. Educational Technology Research and Development, (53), 35-45.

Morrison, R. G., Krawczyk, D., Holyoak, K. J., Hummel, J. E., Chow, T., Miller, B., \& Knowlton, B. J. (2004). A neuro computational model of analogical reasoning and its breakdown in frontotemporal dementia. Journal of Cognitive Neuroscience, 16, 260-271.

Oyler, J. D., Obrzut, J. E., \& Asbjornsen, A. E. (2012). Verbal learning and memory functions in adolescents withreading disabilities. Learning Disability Quarterly, 35, 184-195.

Paas, F., Renkl, A., \& Sweller, J. (Eds.) (2003b). Cognitive Load Theory [special issue]. Educational Psychologist, 38.

Pass, F. G. W. C., \& van Merriënboer, J. J. G. (1994). Variability of worked examples and transfer of geometrical problem solving skills: A cognitive-load approach. Journal of Educational Psychology, 86(1), 122-123.

Passolunghi, M. C., \& Mammarella, I. C. (2012). Selective spatial working memory impairment in children with arithmetic learning disabilities. Journal of Learning Disabilities, 45, 342-351.

Peterson, L., \& Peterson, M. (1959). Short-term retention of individual verbal items. Journal of Experimental Psychology, (58), 193-198.

Piaget, J., Montangero, J., \& Billeter, J. (1977). La formation des correlats. In J. Piaget (Ed.), Recherches sur l'abstraction reflechissante I (pp. 115-129). Paris: Presses Universitaires de France.

Pierce, K. A., and Gholson, B. (1994). Surface similarity and relational similarity in the development of analogical problem solving: Isomorphic and non-isomorphic transfer. Developmental. Psychology. 30, 724-737

Rattermann, M. J., \& Gentner, D. (1998). More evidence for a relational shift in the development of analogy: Children's performance on a causal-mapping task. Cognitive Development, 13, 453-478.

Renkl, A., Atkinson, R. K., \& Grobe C. S. (2004). How fading worked solution step works: A cognitive load perspective. Instructional Science, (32), 59-82.

Richland, L. E., Morrison, R. G., \& Holyoak, K. J. (2006). Children's development of analogical reasoning: Insights from scene analogy problems. Journal of Experimental Child Psychology, 94, 249-273.

Seufert, T., \& Brünken, R. (2006). Cognitive load and the format of instructional aids for coherence formation. Applied Cognitive Psychology, (20), 321-331.

Singer-Freeman, K. E., and Goswami, U. (2001). Does half a pizza equal half a box of chocolates?

Proportional matching in an analogy task. Cognitive. Development. 16, 811-829.

Sternberg, R. J., \& Downing, C. J. (1982). The development of higher-order reasoning in adolescence. Child Development. 53, 209-221.

Sternberg, R. J., \& Nigro, G. (1980). Developmental patterns in the solution of verbal analogies. Child Development. 51,27-38.

Sweller, J. (1988). Cognitive load during problem solving: Effects on learning. Cognitive Science, (12), 257-285.

Thibaut, French \& Vezneva. (2010) The development of analogical making in children's cognitive load and executive function Journal of Experimental Psychology 106, 1-19. 
Toll, S. W., Van der Ven, S. H., Kroesbergen, E. H., \& Van Luit, J. E. (2011). Executive functions as predictors of math learning disabilities. Journal of Learning Disabilities, 44, 521 532.

Tunteler, E., \& Resing, W. C. (2002). Spontaneous analogical transfer in 4-year-olds: a microgenetic study. Journal of Experimental Child Psychology. 83, 149-166.

Van Merriënboer, J. J. G. (2000). The end of software training? Journal of Computer Assisted Learning, 16, 66-375.

Van Merriënboer, J. J. G., \& Sweller, J. (2005). Cognitive load theory and complex learning: Recent developments and future directions. Educational Psychology Review, (17), 147- 177

Viskontas, I. V., Morrison, R. G., Holyoak, K. J., Hummel, J. E., \& Knowlton, B. J. (2004). Relational integration, inhibition and analogical reasoning in older adults. Psychology and Aging, 19, 581-591.

Vosniadou, S. (1995). Analogical reasoning in cognitive development. Metaphor and Symbol, 10, 297-308.

Vygostky. (1978). Mind in society: The development of higher psychological processes. Cambridge, MA: Harvard University

Xiaoning, W. (2014). An empirical study of optimizing cognitive load in multimedia integrated English teaching studies in literature and language. Studies in Literature and Language, 9 (3), 70-76. 